\title{
Os processos interativos no webjorna- lismo audiovisual: um estudo das con- tribuições dos colaboradores aos sites UOL, G1 e Terra
}

\section{Juliana Fernandes Teixeira*}

Resumo: As tecnologias digitais de comunicação tem transformado a produção e a circulação de conteúdos jornalísticos, viabilizando o desenvolvimento de novas formas de socialização de conhecimento caracterizadas pela interatividade. $\mathrm{O}$ artigo apresenta a análise dos modos de utilização da linguagem audiovisual e dos recursos interativos pelos sites jornalísticos mais acessados no Brasil de acordo com o ranking do Alexa. O estudo realizado entre 20 e 27 de setembro de 2009 teve como objeto as seções TV UOL, Vc no G1 e Vc Repórter, dos sites jornalísticos UOL, G1 e Terra. Investigamos, através de uma análise de conteúdo, se e em que medida o webjornalismo audiovisual, associado à participação dos usuários da web, modifica os produtos jornalísticos no ciberespaço. O objetivo é identificar as características da incorporação dos colaboradores nos processos produtivos do webjornalismo audiovisual.

Palavras-chave: webjornalismo audiovisual; jornalismo participativo; interatividade

Resumen: Las tecnologías digitales de comunicación han transformado la producción y la circulación de contenidos periodísticos, permitiendo el desarrollo de nuevas formas de socialización del conocimiento caracterizadas por la interactividad. El artículo presenta el análisis de los modos de utilización del lenguaje audiovisual y de los recursos interactivos por los sitios periodísticos más accesados en Brasil, según el ranking Alexa. El estudio realizado entre 20 y 27 de septiembre de 2009 tenía por objeto las secciones TV UOL, Vc no G1 y Vc Reporter, de los sitios periodísticos UOL, G1 y Terra. Investigamos, a través de un análisis de contenido, si y en qué medida el webperiodismo audiovisual, asociado a la participación de los usuarios de la web, modifica los productos periodísticos en el ciberespacio. El objetivo es identificar las características de la incorporación de los colaboradores en los procesos productivos del webperiodismo audiovisual.

Palabras clave: webperiodismo audiovisual; periodismo participativo; interactividad 
Abstract:The digital technologies of communication have transformed the journalistic contents production and circulation, enabling the development of new forms of knowledge socialization characterized by interactivity. The article presents the analysis of ways of use of audiovisual language and interactive resources by the most accessed news sites in Brazil, according to Alexa ranking. The study carried out between 20 and 27 September 2009 had as its object the sections TV UOL, Vc no G1 and Vc Reporter of the news sites UOL, G1 and Terra. We investigate, through a content analysis, whether and to what extent the audiovisual webjournalism, associated to the web users participation, modifies the journalistic products in cyberspace. The objective is to identify the characteristics of the collaborators incorporation in productive processes of audiovisual webjournalism.

Keywords: audiovisual webjournalism; participatory journalism; interactivity

\section{Introdução}

As novas tecnologias de informação, que tem como elemento central os potenciais oferecidos pela Internet, provocaram transformações de diferentes ordens na sociedade contemporânea (CASTELLS, 1999, pp.49-57). Diante das possibilidades do ciberespaço, é possível perceber mudanças no mundo dos negócios, nas expressões culturais, nas representações das realidades sociais e na forma de produzir e consumir informações, especialmente as jornalísticas (LEMOS, 2004, p.1, p.10, p.18).

Entre as principais características do webjornalismo contemporâneo estão a interatividade, a convergência, a personalização dos conteúdos, a hipertextualidade, a capacidade de armazenamento, a imediaticidade, a multimidialidade e a atualização constante (BARDOEL; DEUZE, 2001, p.1; STOVALL, 2004, p.154; LÓPEZ; OTERO, 2006, p.7; PAVLIK, 2001, p.xi). Segundo Stovall (2004, p.154), cada uma dessas qualidades do meio pode reestruturar os processos de produção da informação jornalística, colocando todos os formatos de jornalismo sob teste (BARDOEL; DEUZE, 2001, p.1). Mas, para Bowman e Willis (2003, p.16), a interatividade é o maior potencial da Era da Informação, embora o alcance das consequências do uso dessa característica ainda dependa da plena consolidação da nova prática no ciberespaço.

Em acordo com López e Otero (2006, p.8), considera-se, nesse artigo, a interatividade como a interação do internauta com o sistema, 
o que permite ao inter-ator absorver a informação da forma desejada. Diante das potencialidades da web, os internautas, cada vez mais, ultrapassam a relativa passividade que era reservada aos telespectadores, ouvintes ou leitores das mídias convencionais (ALVES, 2006, p.95), deixando de ser meros receptores de informação e tornando-se mais ativos - ainda que não completamente - no processo de comunicação.

No webjornalismo audiovisual, a interatividade irá permitir que os internautas não apenas escolham os programas que querem assistir, mas também selecionem determinados segmentos dos programas. Com isso, a tradicional linearidade dos produtos jornalísticos televisivos será desconstruída, já que o internauta que desejar começar pelo final do programa poderá fazer isso (STOVALL, 2004, p.155). Essa ampliação da participação do receptor permitiu a Alves (2006, p.97) apontar a existência de uma "comunicação eu-cêntrica", assim denominada por se basear nas decisões individuais do receptor, diante do leque de opções que a Internet oferece.

A comunicação se torna eu-cêntrica porque tenho acesso somente ao que eu quero, na hora em que eu quero, no formato em que eu quero e onde eu quero. Trata-se, sobretudo, de uma transferência importante de poder ou de privilégio, que passa do emissor para o receptor, numa evidente ruptura dos modelos fechados que se conheciam até agora. (ALVES, 2006, p.97)

Não se deve supor, entretanto, que a interatividade irá abolir os meios de comunicação tradicionais e as formas de representação da realidade através do jornalismo. Em vez disso, é provável que o novo paradigma constituído pelas tecnologias digitais de informação coexista com o paradigma comunicacional tradicional (AFFINI; BURINI, 2009, p.2), gerando uma relação de complementaridade entre os meios e entre os atores sociais envolvidos no processo de comunicação (NEWMAN, 2009 , p.50). De qualquer forma, atualmente, a profissão jornalística, pela primeira vez desde a sua legitimação social como atividade especializada, tem a sua hegemonia como guardiã da informação ameaçada por ferramentas de edição fáceis de usar, conexões permanentes e dispositivos móveis, os quais permitem que a audiência participe da produção das notícias. Nesse contexto, é inevitável que as funções e o status dos jornalistas tradicionais sejam transformados (BARDOEL; DEUZE, 2001, pp.6-7). Diante da interatividade, um dos maiores desafios dos jornalis- 
tas, por exemplo, será produzir as notícias com foco em uma diversidade de atores sociais e com especial atenção a todas as contribuições que chegam pelos distintos canais de participação estabelecidos pelo modelo interativo (LÓPEZ; OTERO, 2006, p.8).

Apesar dos avanços tecnológicos dos últimos anos, o jornalismo digital tem sido muito tímido no que se refere à inovação na produção jornalística. Embora já existam exceções, ainda verificamos o emprego de linguagem simples, baseada principalmente em texto e na reciclagem de material já usado em outro meio, desperdiçando-se as novas possibilidades narrativas que a Internet oferece (ALVES, 2006, p.94). Segundo Becker e Lima (2007, p.22), as tecnologias digitais não tem garantido um jornalismo diferenciado e de qualidade. Mas a qualidade da informação jornalística é fundamental para o desenvolvimento e o aprimoramento do jornalismo participativo emergente. Afinal, como afirma Benedeti (2009, p.51), é de uma informação de qualidade que depende a maior ou menor participação dos cidadãos na esfera pública.

É nesse sentido que a proposta desse trabalho é investigar se e em que medida o webjornalismo audiovisual, associado à participação dos usuários da web, pode promover novos produtos jornalísticos, mais contextualizados, plurais e criativos no ciberespaço. $\mathrm{O}$ objetivo é identificar as características da incorporação dos colaboradores nos processos produtivos do webjornalismo audiovisual. Para isso, realizamos uma análise dos modos de utilização da linguagem audiovisual e dos recursos interativos pelos sites jornalísticos mais acessados no Brasil de acordo com o ranking do Alexa. O estudo, realizado entre 20 e 27 de setembro de 2009, teve como objeto as seções TV UOL , Vc no G1 e Vc Repórter, dos sites jornalísticos UOL, G1 e Terra.

A metodologia empregada foi a análise de conteúdo, uma das mais tradicionais ferramentas de estudo dos produtos jornalísticos. A análise de conteúdo é uma técnica de pesquisa voltada para a descrição objetiva, sistemática e quantitativa do conteúdo manifesto da comunicação (KOLMER, 2008, p.118). Por ser quantitativa, essa metodologia está preocupada com o estabelecimento da distribuição numérica de variáveis e, em seguida, com a realização de inferências a partir dos resultados encontrados. É preciso considerar que a análise de conteúdo permite conhecer o que é publicado pela mídia, mas não possibilita apontar as razões disso, já que esse método foca no estudo dos produtos e não dos processos jornalísticos. 
A análise dos sites jornalísticos proposta por esse artigo pode apontar perspectivas para a maior e melhor incorporação das contribuições dos colaboradores pelos portais jornalísticos, indicando caminhos para o desenvolvimento e o aprimoramento do jornalismo participativo e audiovisual no ciberespaço.

\section{Uma análise comparativa}

A tecnologia digital tem transformado o processo de produção e distribuição de conteúdos, permitindo a emergência de diferentes redes de socialização de conhecimento. Nesse artigo, pretendemos observar se e como o uso da convergência midiática tem promovido novas formas de produção jornalística com conteúdos mais contextualizados, plurais e criativos, e de que forma as possibilidades da interatividade tem estimulado a participação da sociedade na construção das representações dos fatos sociais.

Para investigar em que medida o webjornalismo audiovisual, associado à participação dos usuários da web, modifica os produtos jornalísticos, realizamos entre 20 e 27 de setembro de 2009, sempre entre $18 \mathrm{~h}$ e $20 \mathrm{~h}$, uma análise dos modos de utilização e apropriação da linguagem audiovisual e dos recursos interativos pelos sites jornalísticos mais acessados no Brasil de acordo com o ranking do Alexa. O estudo teve como objeto as seções TV UOL, Vc no G1 e Vc Repórter, dos sites jornalísticos UOL, G1 e Terra, conforme já mencionado. Todas essas editorias procuram promover interatividade no tratamento das notícias e utilizam a linguagem audiovisual na publicação de conteúdos.

Utilizamos como metodologia a análise de conteúdo, que, como já destacado, visa a descrição objetiva, sistemática e quantitativa do conteúdo manifesto dos produtos jornalísticos, a partir de diferentes variáveis. Acreditamos que esse método nos permitirá identificar as principais características de cada um dos sites jornalísticos analisados, propondo alternativas para o desenvolvimento dos processos interativos, especialmente aqueles que incorporam conteúdos audiovisuais.

A primeira categoria de análise propõe um estudo sobre o contrato de interação estabelecido entre o site jornalístico e os colaboradores, ou seja, as regras estipuladas, implícita ou explicitamente, para essa relação. Observamos, especialmente, as cessões de direito e os termos de 
uso aos quais os colaboradores são submetidos quando enviam contribuições para os sites estudados.

A segunda categoria pretende investigar os mecanismos de publicação, estudando as ferramentas oferecidas pelos sites para que os colaboradores enviem suas contribuições. A terceira observa a forma de disponibilização das contribuições dos colaboradores nos sites analisados. Buscando identificar qual relevância os sites jornalísticos conferem às contribuições, estudamos as diferentes formas de apresentação das colaborações e avaliamos qual relação estabelecem com o conteúdo dos portais informativos como um todo.

$\mathrm{Na}$ quarta categoria, audiovisualidade/textualidade, analisamos se os colaboradores enviam materiais audiovisuais como colaborações. Além disso, pretendemos identificar as principais características, como tempo de duração e tipos de edição, dos vídeos enviados pelos colaboradores. A quinta categoria procura verificar o caráter jornalístico das contribuições, em função de aspectos como a temática e a abordagem do material enviado. E a sexta categoria analisa a periodicidade na publicação de informações nos sites pesquisados, assim como o tempo médio entre as contribuições originais e suas atualizações. Os principais resultados da análise são apresentados a seguir.

\section{TV UOL}
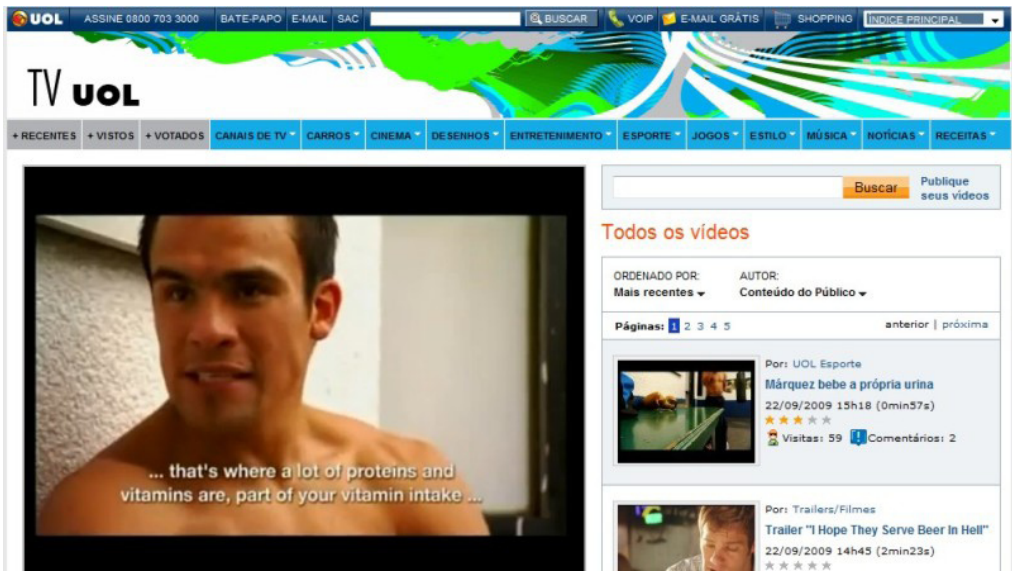

Figura 1 - Página principal das contribuições da TV UOL no dia 22 de setembro de 2009. 
Contrato de interação - A TV UOL não impõe restrições às contribuições. Os colaboradores não são submetidos a qualquer regra para o uso do sistema e para a publicação de arquivos de vídeo, os quais são disponibilizados automaticamente no site. Ou seja, não há qualquer seleção dos materiais publicados pela equipe do portal UOL.

Mecanismos de publicação - Os vídeos enviados pelos colaboradores são publicados através do sistema UOL Mais, um serviço que permite publicar vídeos, fotos e textos num único lugar. Para ingressar no sistema, é necessário que o colaborador tenha um e-mail UOL ou BOL, ou realize um cadastro gratuito. Ao publicar um vídeo, é preciso identificá-lo através de um título, uma descrição e etiquetas de acordo com o seu conteúdo. Os vídeos devem ter um tamanho máximo de $100 \mathrm{Mb}$.

Forma de disponibilização - As contribuições são apresentadas junto com os conteúdos produzidos pela redação do portal. Para realizar a separação entre os dois tipos de publicação, é necessário clicar na opção Autor/Conteúdo do Público, localizada à direita da página principal. Mas, sempre que se clica em alguma das editorias do portal, é preciso selecionar novamente a opção Autor/Conteúdo do Público, o que revela que o objetivo não é manter o internauta restrito aos conteúdos dos colaboradores.

Audiovisualidade/textualidade - A primeira página das contribuições sempre apresenta seis vídeos. A duração dos materiais audiovisuais analisados variou entre 7” e 9’32”. Em média, 53\% dos vídeos sofrem edição e $39 \%$ não são editados, o que representa um total de $92 \%$ de colaborações efetivamente audiovisuais. Os outros $8 \%$ das contribuições, embora sejam postados como vídeos pelos colaboradores, são apresentações de slides compostas por fotos e músicas ao fundo. Entre os vídeos editados, parte expressiva é constituída de clipes (21\%), trailers (16\%) e reportagens ou publicidades produzidas originalmente para a mídia tradicional (37\%).

Caráter jornalístico - Pode-se afirmar que 25\% dos vídeos publicados por colaboradores são jornalísticos no que se refere à temática. Entre esses, 78\% seguem o formato jornalístico tradicional, seja através da forma de flash (34\%), seja através da forma de VT (44\%). Os outros vídeos jornalísticos postados pelos colaboradores, que correspondem a $22 \%$, são registros de acontecimentos e flagrantes de cenas inusitadas.

Periodicidade - Os vídeos são apresentados na ordem cronológica de publicação, o que demonstra a relevância conferida pelo site 
à atualidade dos vídeos. Durante a análise, registramos que as últimas postagens oscilavam entre às $17 \mathrm{~h} 32$ do mesmo dia até dois dias antes. Mas, em média, as últimas contribuições do site eram registradas cerca de $3 \mathrm{~h}$ antes da análise do material.

\section{Ve no G1}

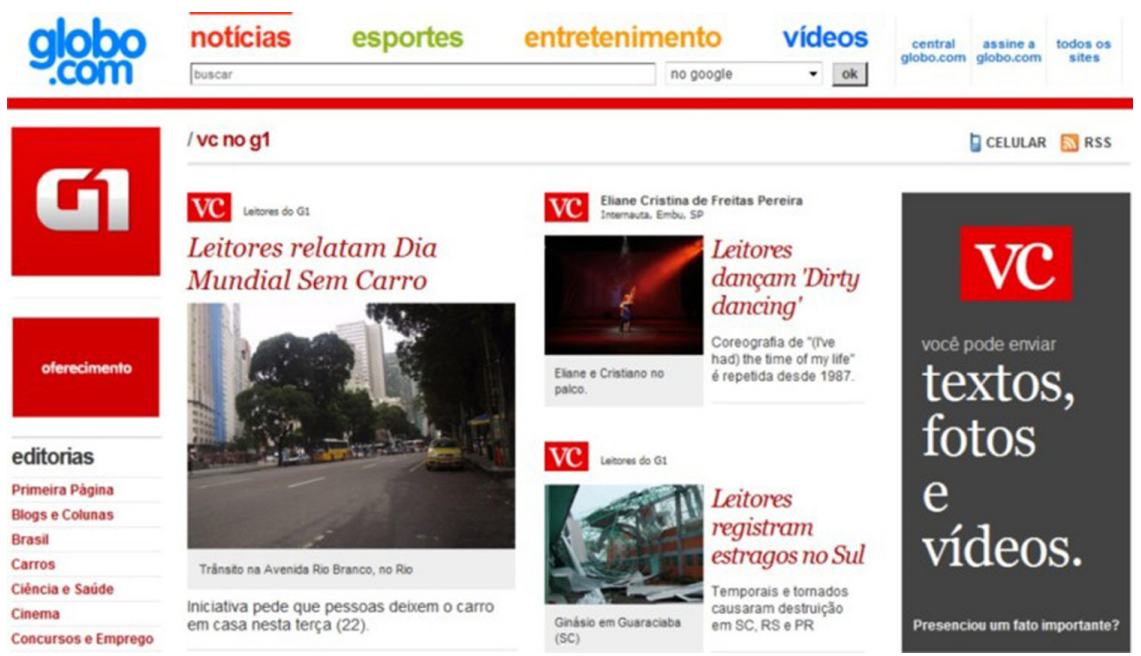

Figura 2 - Página principal do Vc no G1 no dia 22 de setembro de 2009.

Contrato de interação - Para enviar contribuições, deve-se aceitar um termo de uso, apresentado no momento em que se realiza o cadastro no sistema de publicações. O objetivo do termo é regulamentar a utilização do site e, para isso, é necessário que seja aceito sem reservas pelo colaborador. $\mathrm{O}$ documento apresenta oito cláusulas, as quais abordam questões como os direitos e as responsabilidades dos colaboradores e a cessão total e irrestrita dos direitos referentes aos materiais enviados ao portal. Evidencia-se, ainda, que as contribuições devem ter conteúdo jornalístico, sejam elas textos, fotos ou vídeos.

Mecanismos de publicação - $\mathrm{O}$ acesso ao sistema de publicação depende da realização de um cadastro gratuito. Depois de realizar o login, o colaborador tem acesso a uma página em que são disponibilizados espaços para o título, o assunto e o texto da notícia. Também é preciso selecionar qual o tipo do conteúdo que se deseja enviar: apenas 
texto; texto+foto ou texto+vídeo. Quando se clica em uma das duas últimas opções, uma nova parte da página se abre automaticamente para que o colaborador anexe o material - que deve ter até $50 \mathrm{Mb}$ - e escreva a sua legenda. Mas, as contribuições não são publicadas automaticamente no portal, ou seja, são submetidas à avaliação da equipe do Vc no G1.

Forma de disponibilização - Geralmente, há uma chamada principal, com dois destaques secundários ao lado. Em seguida, são disponibilizadas as demais contribuições em ordem cronológica. Todas as colaborações da primeira página são acompanhadas de uma foto. É comum a publicação de coletâneas das contribuições de diferentes colaboradores sobre um mesmo assunto, o que evidencia a edição realizada pelo site. Como as contribuições dos colaboradores do portal G1 são disponibilizadas em uma editoria específica, a Vc no G1, essa editoria não dispõe de subeditorias para a organização dos materiais recebidos. Desse modo, a divisão temática das contribuições, em geral, acontece dentro da própria primeira página do site. Entre essas divisões, é possível destacar: brasileiros no exterior, vc sósia, carros antigos, bichos e vídeos.

Audiovisualidade/textualidade - Durante a análise, o site apresentou apenas cinco vídeos. Entre as 26 contribuições disponibilizadas diariamente, em média, na primeira página do portal, apenas três eram audiovisuais, o que corresponde a 11,5\%. Além disso, é frequente a repetição dos mesmos vídeos por vários dias. A duração dos materiais audiovisuais analisados variou entre 11" e 3'10”, mas apenas um dos vídeos teve mais que 1'00. Os outros quatro não passaram dos 52”. Nenhum dos vídeos sofreu edição de imagens, até porque se constituem de flagrantes de acidentes e assaltos. Em apenas um dos vídeos aparece a voz do colaborador, o que não se caracteriza como um off, já que a pessoa está comentando o que está gravando com outra.

Caráter jornalístico - Embora o termo de uso defina o caráter jornalístico como essencial para a publicação de conteúdos, nem todas as contribuições são diretamente voltadas para o relato de fatos. Em média, 15 das 26 chamadas diárias da primeira página podem ser consideradas jornalísticas, o que corresponde a 58\%. Quando nos referimos apenas aos vídeos, pode-se afirmar que todas as contribuições possuem temáticas jornalísticas, mas nenhuma segue os formatos telejornalísticos tradicionais de VTs ou flashes, até porque são apenas registros e flagrantes, conforme já mencionado.

Periodicidade - As contribuições são apresentadas na ordem cronológica de publicação. Mas, em alguns dias da análise, verificamos 
que as matérias em destaque não eram as mais recentes da página, o que gerou uma dúvida quanto ao critério definido pelo portal nesse sentido. Em uma análise de conteúdo como essa não é possível afirmar com precisão o motivo disso, mas podemos descartar a possibilidade de que esse fato se devia a uma maior importância do tema do destaque, pois uma das matérias preteridas como chamada principal embora fosse a atualizada mais recentemente, se referia a um incêndio ocorrido no metrô de São Paulo, a qual teria um valor-notícia mais expressivo caso fosse comparada a fotos sobre a primavera. As postagens, em média, ocorreram $5 \mathrm{~h}$ antes da análise, e as atualizações, cerca de $1 \mathrm{~h} 30$ depois da primeira publicação.

\section{Vc Repórter}

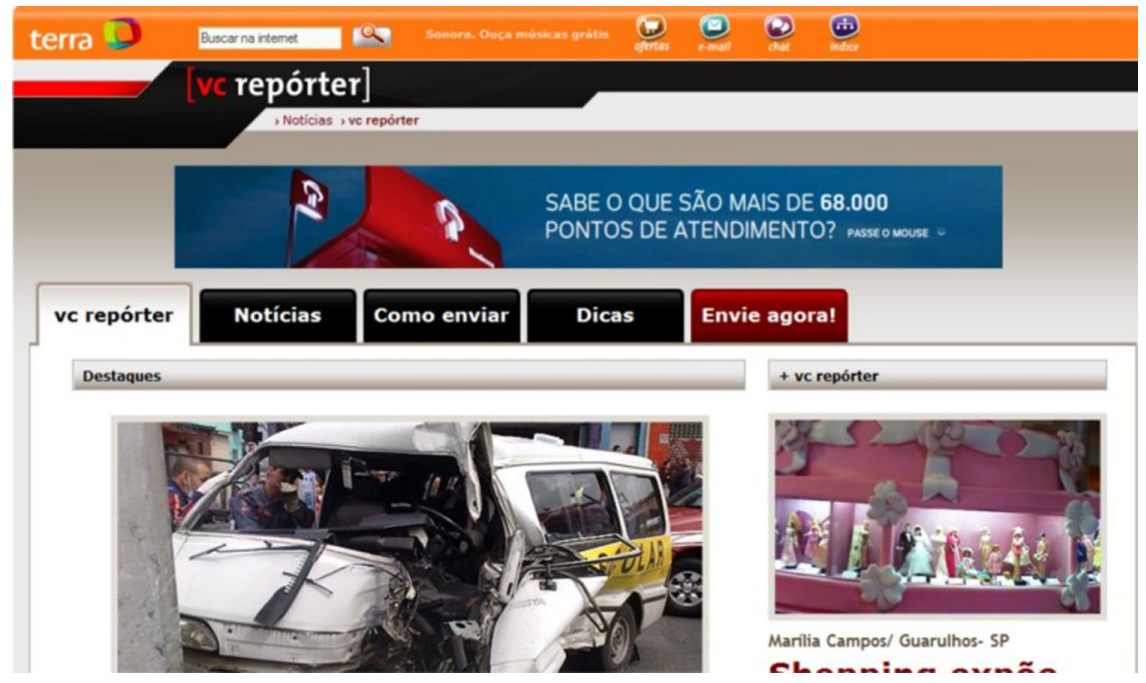

Figura 3 - Página principal do Vc Repórter no dia 25 de setembro de 2009.

Contrato de interação - Para o envio de contribuições, devese autorizar a utilização do material pelo portal Terra e seus parceiros, dentro das condições impostas pela cessão de direitos disponibilizada na seção "Envie agora". Ao aceitar esse termo, o colaborador realiza a cessão dos direitos sobre o conteúdo. Além de indicar a necessidade de preenchimento de um cadastro gratuito, o documento explicita que o 
material poderá ou não ser publicado, em função dos critérios estabelecidos pelo portal e sem limitação de prazo.

Mecanismos de publicação - $\mathrm{O}$ envio das contribuições ocorre através da seção "Envie agora", onde se deve preencher um cadastro, anexar o arquivo desejado - com no máximo $10 \mathrm{Mb}$ - e selecionar o seu formato (foto, vídeo ou texto). Em seguida, deve-se descrever o material anexado e informar o local e a data da notícia. Mas, conforme explicitado na cessão de direitos, a publicação no site não é automática, já que há uma seleção e uma edição por parte da equipe do Vc Repórter.

Forma de disponibilização - A primeira página sempre apresenta um destaque principal, uma chamada secundária ao lado e duas outras chamadas abaixo. Em geral, esses destaques apresentam as contribuições mais recentes. É comum que, ao abrir algumas matérias, o internauta seja direcionado para páginas das editorias de trânsito ou de cinema do portal Terra, as quais possuem layouts diferentes do adotado no Vc Repórter. Isso evidencia que, por vezes, há uma apropriação das contribuições pelo Terra, mas não configura uma mistura entre os conteúdos dos colaboradores e do portal. Afinal, além do $V_{c}$ Repórter ser uma seção específica e claramente identificável, todas as contribuições recebem a etiqueta "vc repórter" antes do título.

Audiovisualidade/textualidade - A primeira página não apresentou nenhum material audiovisual durante a análise. Os únicos vídeos encontrados no site estavam localizados à direita das páginas internas das reportagens em destaque e, ainda assim, era preciso selecionar essa opção entre outras duas (notícias e fotos). Porém, os três vídeos apresentados ao internauta eram sempre os mesmos e não eram contribuições enviadas pelos colaboradores, mas vídeos produzidos pelo Terra e pela Band News.

Caráter jornalístico - Durante a análise, todas as quatro reportagens apresentadas diariamente na primeira página tinham características jornalísticas. O esforço do portal em aplicar um caráter jornalístico a essa editoria fica evidente, ainda, nas instruções apresentadas no momento do preenchimento do formulário da contribuição: "Descreva a notícia que você está mandando. Para ter maior chance de publicação, inclua informações e detalhes que respondam a perguntas básicas, como 'quem, o que, onde e quando'." Isso revela que o portal tenta repassar aos colaboradores as técnicas jornalísticas utilizadas pela própria redação. Vale mencionar também que, na seção "Dicas", são apresentadas 
sugestões sobre como elaborar um bom texto, foto ou vídeo, segundo os critérios do Terra.

Periodicidade - Embora os destaques da primeira página sejam geralmente as contribuições mais recentes, conforme já evidenciado, uma observação da seção "Notícias" revela que essa não é uma regra. Essa constatação foi possível no dia 26 de setembro, quando a notícia sobre o assassinato de pai e filho em Santo André foi preterida em comparação à matéria de um outdoor censurado, publicada ainda no dia anterior. Além disso, é recorrente a repetição de destaques durante dois dias seguidos, mesmo que em posições distintas na página principal. Mas, em geral, a postagem do destaque principal acontece $1 \mathrm{~h} 30$ antes da análise. As atualizações são bastante comuns, já que foram verificadas em $66 \%$ das 32 reportagens em destaque na primeira página durante a análise.

\section{Resultados da análise}

Com base na análise realizada, é possível concluir que ainda não há um padrão entre os sites jornalísticos quanto à disponibilização das contribuições. Enquanto o portal UOL apresenta o conteúdo do internauta junto com o da sua redação, o G1 e o Terra dedicam seções específicas para as colaborações. Essa separação revela que, embora os portais compreendam a relevância da integração do colaborador no processo de produção jornalística, ainda há restrições à apropriação dessas contribuições, as quais, caso divulguem informações impróprias ou inadequadas, podem comprometer a credibilidade já conquistada pelos portais.

A preocupação com a credibilidade fica ainda mais evidente quando analisamos os termos de uso estabelecidos pelos sites Vc no G1 e Vc Repórter. Diferentemente da TV UOL, a qual não impõe restrições às contribuições, as editorias interativas do G1 e do Terra são regulamentadas por uma série de regras, o que tem consequências sobre o caráter mais ou menos jornalístico dos sites, até porque é uma equipe de jornalistas que seleciona as informações a serem publicadas, atendendo aos critérios utilizados pelo próprio portal. $\mathrm{O}$ menor número de contribuições jornalísticas da TV UOL, em comparação aos outros dois sites (vide Gráfico 1), corrobora esta afirmação. Ou seja, como a TV UOL não estabelece restrições ou realiza uma seleção dos materiais recebidos, 
muitos não atendem aos critérios de noticiabilidade e aos valores-notícias característicos do jornalismo.

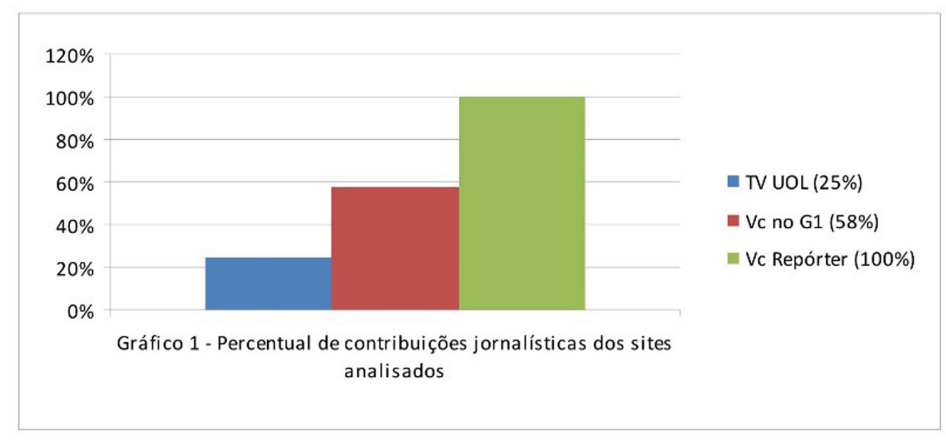

Mas, talvez, as regulamentações impostas por alguns sites estejam comprometendo a periodicidade e a audiovisualidade das contribuições. Isso porque, embora os sites demonstrem uma preocupação com a atualidade ao disponibilizar as contribuições em ordem cronológica, as repetições de reportagens e até de páginas inteiras - como aconteceu com o Vc no G1 no dia 26 de setembro - são recorrentes. Isso revela uma incapacidade dos colaboradores enviarem contribuições jornalísticas com a mesma periodicidade como ocorre com outros conteúdos. Essa deficiência é acentuada quando nos referimos aos conteúdos audiovisuais, os quais já possuem normalmente uma maior dificuldade de produção, tanto que a TV UOL, mesmo permitindo a publicação de vídeos de entretenimento, chegou a repetir a mesma página do dia 26 no dia 27 de setembro. Contudo, a situação do Vc Repórter, nesse sentido, foi pior, já que o site não ofereceu, durante toda a análise, nenhum vídeo enviado pelos colaboradores, conforme evidencia o Gráfico 2.

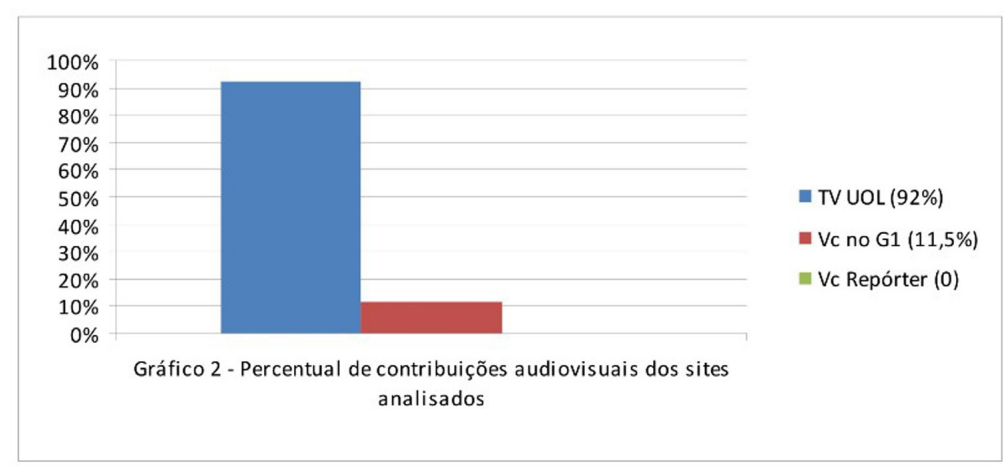


É necessário salientar, ainda, que a seleção e edição prévia dos editores pode fazer com que os sites percam a oportunidade de realizar furos jornalísticos com base nas contribuições dos colaboradores. Afinal, por mais que o colaborador envie uma notícia exclusiva, a sua publicação dependerá da autorização da equipe do portal, tempo que pode ser crucial na divulgação de uma informação jornalística.

Enfim, as seções TV UOL, Vc no G1 e Vc Repórter, dos sites jornalísticos UOL, G1 e Terra, já apresentam alternativas bem sucedidas de interação com os internautas, especialmente no que diz respeito aos mecanismos de publicação, cada vez mais simples e fáceis de operar. Mas, ainda é preciso que sejam desenvolvidas formas de estimular e facilitar contribuições jornalísticas, principalmente em formato audiovisual, o que se constitui como uma das principais deficiências desses portais atualmente.

\section{Considerações finais}

A sociedade contemporânea vivencia um momento de transição diante das novas tecnologias de informação, no qual alcançarão sucesso apenas os meios de qualidade, caracterizados por conteúdos exclusivos e contextualizados, marcados pela interatividade, pela hipertextualidade e pela multimidialidade, oferecidos em diferentes formatos, e formulados por jornalistas bem treinados (PAVLIK, 2001, p.217; QUINN, 2005, p.196). Nesse sentido, é possível afirmar que as estratégias para o webjornalismo audiovisual devem se centrar mais nos conteúdos que nos suportes (VIVAR; GUADALUPE, 2005, p.80), e que as inovações devem emergir como o desdobramento das formas narrativas antigas (PINTO, 2005, p.285).

Hoje, quando as atividades de ver TV e acessar a Internet se misturam, é possível observar que as narrativas dos noticiários televisivos e do webjornalismo audiovisual se tornam cada vez mais híbridas. Mas, o problema está no fato de que muitas vezes os mesmos conteúdos jornalísticos audiovisuais veiculados nos telejornais são publicados na Internet. Além disso, os sites audiovisuais que produzem conteúdos exclusivos para o ciberespaço ainda experimentam os primeiros passos em direção a uma gramática própria (BECKER; LIMA, 2007, p.14). 
Experiências de webjornalismo audiovisual como as dos sites jornalísticos analisados evidenciam que, embora as novas tecnologias já possibilitem inovações, ainda são tímidas as iniciativas de aproveitar a convergência para a produção de vídeos jornalísticos mais contextualizados e com estéticas mais criativas, inclusive no jornalismo participativo. A maior parte das contribuições que utilizam o formato audiovisual reproduz as características de linguagem e a estrutura narrativa dos telejornais ou apresentam apenas registros rápidos e sem edição de acontecimentos. $\mathrm{E}$ os internautas nem sempre podem estabelecer uma relação efetivamente simétrica com os jornalistas.

De qualquer modo, a perspectiva do internauta como colaborador no processo de comunicação já subverte a forma de distribuição unilateral de informações, e aponta para uma nova maneira de pensar a relação entre produtores e consumidores, entre jornalistas e cidadãos, entre os veículos de comunicação e a sociedade. Esse novo cenário pode trazer mudanças expressivas para a produção jornalística audiovisual realizada atualmente, uma vez que a inserção de novos sujeitos na produção da mídia gera mudanças estéticas e nas linguagens e formas narrativas (BECKER; TEIXEIRA, 2008, p.13).

É verdade que o desenvolvimento da tecnologia digital, a evolução dos modos de transmissão e a compressão de dados estimulam a produção e a publicação de vídeos na Internet. Mas, é preciso considerar que os custos para um site manter uma conexão com capacidade de armazenar e disponibilizar conteúdos audiovisuais, e para um internauta produzir textos de qualidade em áudio e vídeo ainda são muito altos. Por isso, é preciso superar a falta de recursos não apenas com criatividade e capacidade de partilhar conteúdos, mas também adotando processadores baratos de distribuição e armazenamento de informações, especialmente na cadeia produtiva do audiovisual digital (BECKER; TEIXEIRA, 2009, pp.11-13). Segundo Machado (2009, p.229-230), temos algumas opções baratas e simples para produzir conteúdos audiovisuais, como é o caso das webtvs, que têm se disseminado na Internet, adotando uma resolução muito baixa para garantir a oferta rápida e fácil de conteúdos aos internautas.

As transformações provocadas pelas tecnologias de informação tem gerado mudanças em diferentes setores da vida social e efeitos expressivos na produção e na recepção de notícias. Mas, ainda não sabemos se esse processo, representado principalmente pelas experiências de jornalismo participativo, oferecerá um jornalismo de maior qualidade, 
marcado por notícias mais criativas, contextualizadas e plurais. A única certeza é que em meio à proliferação de sites com diferentes formatos e conteúdos, continuará havendo lugar para o jornalismo (LÓPEZ, 2006, p.xi; ALVES, 2006, pp.101-102; MEDITSCH, 2006, p.9). Mas, certamente, será fundamental pensarmos uma nova forma de produção jornalística, gerando um webjornalismo com uma nova linguagem, que aproveite de maneira diferenciada todas as potencialidades da web e das futuras plataformas digitais.

\section{Referências}

AFFINI, Letícia; BURINI, Débora. Era Digital: o texto audiovisual na web. Trabalho apresentado no XXXII Congresso Brasileiro de Ciências da Comunicação. Curitiba: 4 a 7 de setembro de 2009.

ALVES, Rosental Calmon. Jornalismo Digital: Dez anos de web... e a revolução continua. Revista Comunicação E̋ Sociedade. São Paulo: Universidade Metodista, vol. 9-10, 2006, pp.93-102.

BARDOEL, Jo; DEUZE, Mark. Network Journalism: Converging Competences of Media Professionals and Professionalism. Australian Journalism Review, 23 (2), 2001, pp.91-103.

BECKER, Beatriz; LIMA, Marcos Henrique. Ame ou Deixe o Ciberespaço. Estudos em Jornalismo e Midia. Ano IV - n. 2 - p. 11 a 23 - 2007.

BECKER, Beatriz; TEIXEIRA, Juliana. O Telejornalismo na Era Digital. In: $6^{\circ}$ Encontro Nacional de Pesquisadores em Jornalismo - SBPJOR. Coordenada: Telejornalismo e Contemporaneidade: Representação e Produção de Sentidos Públicos. São Bernardo do Campo - SP, 2008.

Um panorama da produção jornalística audiovisual no ciberespaço, as experiências das redes colaborativas. XVIII Encontro Anual da Compós - GT Estudos de Jornalismo. Belo Horizonte - MG, 2009.

BENEDETI, Carina Andrade. A Qualidade da Informação Jornalística - Do conceito à prática. Série Jornalismo a Rigor. V.2. Florianópolis: Insular, 2009. 
BOWMAN, Shayne; WILLIS, Chris. Nosostros, el medio - Cómo las audiencias están modelando el futuro de la noticias y la información. Trad Guillermo Franco. Colômbia: El Tiempo, 2003.

CASTELLS, Manuel. A sociedade em rede: a era da informação: economia, sociedade e cultura. São Paulo: Paz e Terra, 1999.

KOLMER, Christian. Methods of Journalism Research - Content Analysis. In: LÖFFELHOLZ, Martin; WEAVER, David (orgs.). Global Journalism Research: theories, methods, findings, future. Reino Unido: Blackwell Publishing Ltd, 2008, p.117-130.

LEMOS, André. Cibercultura e Mobilidade: a Era da Conexão. Revista Razón y Palabra. Out-Nov, 2004. Disponível em <http://www.facom. ufba.br/ciberpesquisa/andrelemos/ cibermob.pdf $>$. Acesso em $28 \mathrm{de} \mathrm{ou-}$ tubro de 2009.

LÓPEZ, Xosé. Presentación. In: LÓPEZ, Xosé (org.). Sistemas digitales de información. Madrid: Pearson Educación, 2006, pp. vii-xv.

LÓPEZ, Xosé; OTERO, Marita. Ciberperiodismo: de la niñez a la mayoría de edad. In: LÓPEZ, Xosé (org.). Sistemas digitales de información. Madrid: Pearson Educación, 2006, pp. 1-26.

MACHADO, Arlindo. O mito da alta definição. In: SQUIRRA, Sebastião e FECHINE, Yvana (orgs.). Televisão Digital: desafios para a comunicação. Livro da COMPÓS - 2009. Porto Alegre: Sulina, 2009, p. 223-230.

MEDISTSCH, Eduardo. Novas e velhas tendências: os dilemas do ensino de jornalismo na sociedade da informação. Texto baseado na $\mathrm{Pa}-$ lestra de Abertura do $9^{\circ}$ Encontro do Fórum Nacional de Professores de Jornalismo. Campos de Goytacazes, Rio de Janeiro: 2006.

NEWMAN, Nic. The rise of social media and its impact on mainstream journalism: a study of how newspapers and broadcasters in the UK and US are responding to a wave of participatory social media, and a historic shift in control towards individual consumers. Oxford: Reuters Institute for the study of journalism, 2009.

PAVLIK, John Veron. Journalism and new media. New York: Columbia University, 2001. 
PINTO, Álvaro Vieira. O conceito de tecnologia. Vol. 1. Rio de Janeiro: Contraponto, 2005.

QUINN, Stephen. Convergent journalism: the Fundamentals of multimedia reporting. New York: Peter Lang Publishing, 2005.

STOVALL, James Glen. Web journalism: practice and promise of a new medium. EUA: Pearson Education, 2004.

VIVAR, Jesús Flores; GUADALUPE, Guadalupe Aguado. Modelos de negocio em el ciberperiodismo. Madri: Editorial Fragua, 2005.

\section{Notas}

[1] Uma grande quantidade de informações, como é possível verificar hoje na Internet, não é sinônimo de qualidade de informação. Segundo Benedeti (2009, p.113), a qualidade implica tanto o conhecimento das características específicas do que se qualifica, quanto a sua avaliação a partir de um parâmetro de aceitação, um referencial de qualidade (BENEDETI, 2009, p.113). Abordar a qualidade através desta perspectiva nos permite identificar as características, limitações e potencialidades da informação jornalística e, a partir daí, apresentar alguns elementos que sirvam de referência para a sua avaliação. Benedeti (2009, p.119) sistematizou sete desses elementos: (1) veracidade; (2) comunicabilidade; (3) pluralidade e imparcialidade; (4) independência e universalidade; (5) interesse público; (6) inteligibilidade; e (7) transmissibilidade, transparência do método e do rigor investigativo.

[2] No jornalismo participativo, a interatividade é o potencial da Internet que mais se destaca, na medida em que representa a apropriação das tecnologias digitais para o estabelecimento de novas relações e mediações sócio-culturais na produção jornalística. Empregamos nesse estudo a definição de jornalismo participativo proposta por Bowman e Willis (2003, p.9): "é o ato de um cidadão ou de um grupo de cidadãos que desempenham um papel ativo no processo de coletar, reportar, analisar e disseminar informação. O objetivo desta participação é oferecer informação independente, segura, exata, ampla e relevante que a democracia exige". As diferenças mais notórias entre o jornalismo participativo e o jornalismo tradicional estão nas suas estruturas e na sua organização. Os meios tradicionais são criados por entidades hierárquicas, voltadas para o comércio, cujo modelo de negócios e organização é centrado na emissão, no fluxo de trabalho editorial e na rentabilidade. Já o jornalismo participativo é criado por comunidades em rede que valorizam o debate, a colaboração e o igualitarismo mais que o lucro. Mas, é preciso evidenciar que a Internet também é um mecanismo de edição e seleção, assim como os veículos tradicionais, com a diferença de que o julgamento editorial se aplica depois da publicação e não antecipadamente (BOWMAN; WILLIS, 2003, p.13). 
Juliana Fernandes Teixeira

[3] http://tvuol.uol.com.br/

[4] http://g1.globo.com/VCnoG1/

[5] http://noticias.terra.com.br/vcreporter

* Juliana Fernandez Teixeira

Mestranda do Programa de

Pós-graduação em Jornalismo da Universidade Federal de Santa Catarina (UFSC).

\section{E-mail:}

julianafernandesrj@yahoo.

com.br 